\title{
Correction to: Water-induced erosion potentiality and vulnerability assessment in Kangsabati river basin, eastern India
}

\author{
Rabin Chakrabortty ${ }^{1}$. Subodh Chandra Pal ${ }^{1}$ (D . Alireza Arabameri ${ }^{2}$. \\ Phuong Thao Thi $\mathrm{Ngo}^{3}$ - Indrajit Chowdhuri ${ }^{1}$ - Paramita Roy ${ }^{1}$. Sadhan Malik ${ }^{1}$. \\ Biswajit Das ${ }^{1}$
}

Published online: 5 August 2021

(c) Springer Nature B.V. 2021

\section{Correction to: Environment, Development and Sustainability https://doi.org/10.1007/s10668-021-01576-w}

In the original publication of the article [1], affiliation of the authors Subodh Chandra Pal Indrajit Chowdhuri, Paramita Roy, Sadhan Malik and Biswajit Das has been wrongly indicated as "Department of Geomorphology, Tarbiat Modares University, 14117-13116 Tehran, Iran". The correct affiliation of the author's is "Department of Geography, The University of Burdwan, Bardhaman, West Bengal, India".

Affiliation of the authors has been corrected in the original publication.

The original article can be found online at https://doi.org/10.1007/s10668-021-01576-w.

Subodh Chandra Pal

geo.subodh@gmail.com

Rabin Chakrabortty

rabingeo8@gmail.com

Alireza Arabameri

alireza.ameri91@yahoo.com

Phuong Thao Thi Ngo

Ngotphuongthao5@duytan.edu.vn

Indrajit Chowdhuri

indrajitchowdhuri@gmail.com

Paramita Roy

paramitaroy95@gmail.com

Sadhan Malik

sadhanmalik06@gmail.com

Biswajit Das

biswajitdas1119@gmail.com

1 Department of Geography, The University of Burdwan, Bardhaman, West Bengal, India

2 Department of Geomorphology, Tarbiat Modares University, 14117-13116 Tehran, Iran

3 Institute of Research and Development, Duy Tan University, Da Nang 550000, Vietnam 
Publisher's Note Springer Nature remains neutral with regard to jurisdictional claims in published maps and institutional affiliations. 